\title{
From Document Centric Approach to MBSE Approach: BPMN, UML, SysML and Wire Framing Implementation
}

\author{
David Schumacher ${ }^{(\varpi)}$ \\ Thales Services, 110 rue Blaise Pascal, Immeuble Viséo, \\ 38334 Montbonnot Cedex, France \\ david.schumacher@thalesgroup.com
}

\begin{abstract}
Model Based System Engineering (MBSE) approach aims among other to achieve the business objectives for complex/critical systems. This approach is so intended to enhance understanding and quality. Several choices shall be made and shall allow to build a good model which means that is usable and understandable by all stakeholders in order to share and support complex system requirements, business analysis, architecture, design, and verification \& validation activities.

To maximize number and various stakeholders, we though language(s) have to be rightly selected.

So, we will discuss an example of a framework implementation based on: BPMN, UML, SysML and wire framing in order to tempt to improve of collaboration, to improve impact assessments and to share the understanding in product development between teams for two different project: IT project (web software context) and a class III medical critical system (hardware and software context).
\end{abstract}

